\title{
Desarrollo turístico y conflictos en el centro histórico de Villa de Leyva, Colombia
}

\author{
Yarleys Pulgarín Osorio ${ }^{1}$ y Juliana Dávila Gamboa ${ }^{2}$
}

\begin{abstract}
Resumen: El presente trabajo pretende plantear una reflexión acerca de algunos problemas derivados de la irrupción de la actividad turística no planificada en los centros históricos, particularmente el de Villa de Leyva, localizada en la zona andina central de Colombia. Para tal fin se recoge la experiencia de la participación en diversos proyectos de investigación a lo largo de una década y las discusiones abordadas desde la academia, así como la consulta del trabajo teórico de expertos que aportan un sustento conceptual que contribuye a explicar los fenómenos que tienen lugar en la zona de estudio. Como se podrá ver, diversas dinámicas que se han exacerbado desde mediados de los años 70 tales como la turistificación, la gentrificación y el desarrollo inmobiliario carente de control, están amenazando aquellos valores que en su momento llevaron este lugar a la máxima categoría de declaratoria del patrimonio cultural en Colombia.
\end{abstract}

Palabras clave: patrimonio cultural; centros históricos; desarrollo turístico; Colombia.

\section{Desenvolvimento turístico e conflitos no centro histórico de Villa de Leyva, Colômbia}

Resumo: O presente trabalho pretende levantar uma reflexão sobre alguns problemas derivados da irrupção da atividade turística não planejada nos centros históricos, particularmente o de Villa de Leyva, localizado na zona andina central da Colômbia. Para tanto, são coletadas as experiências de participação em vários projetos de pesquisa ao longo de uma década e as discussões abordadas na academia, bem como a consulta do trabalho teórico de especialistas que fornecem um suporte conceitual que ajuda a explicar os fenômenos que ocorrem na área de estudo. Como poderemos ver, várias dinâmicas exacerbadas desde meados da década de 1970, como turismo, gentrificação e incorporação imobiliária sem controle, ameaçam os valores que outrora levaram esse lugar à mais alta categoria de declaração da patrimônio cultural na Colômbia.

Palavras-chave: patrimônio cultural; centro histórico; desenvolvimento turístico; Colômbia.

\section{Tourism development and conflicts in the historic center of Villa de Leyva, Colombia}

Abstract: The present paper intends to raise a reflection on some problems derived from the irruption of the unplanned tourist activity in the historical centers, particularly that of Villa de Leyva, located in the central Andean zone of Colombia. For the sake of this, the experience of participation in various research projects throughout a decade and the discussions approached from the academy are gathered, as well as the consultation of the theoretical work of experts who provide a conceptual support that contributes to explain the phenomena that take place in the study area. As it can be seen, various dynamics that have been exacerbated since the mid-1970s such as tourism, gentrification and real estate development without control, are threatening those values that once led this place to the highest category of declaration of the cultural heritage in Colombia.

Keywords: cultural heritage; historic centers; touristic development; Colombia.

\section{(c) (i) $\odot$}

DOI: https://doi.org/10.26512/patryter.v4i7.27406

Como citar este artigo: Pulgarín-Osorio, Y.; Dávila-Gamboa, J. (2021). Desarrollo turístico y conflictos en el centro histórico de Villa de Leyva, Colombia. PatryTer - Revista Latinoamericana e Caribenha de Geografia e Humanidades, 4 (7), 12-27. DOI: https://doi.org/10.26512/patryter.v4i7.27406

Recebido: 01 de outubro de 2019. Aceite: 10 de junho de 2020. Publicado: 01 de março de 2021.

${ }^{1}$ Docente de la Universidad de La Salle de Bogotá. ORCID: https://orcid.org/0000-0002-3122-4766. E-mail: ypulgarin@unisalle.edu.co.

2 Investigadora de la Fundación Erigaie, Bogotá. ORCID: https://orcid.org/0000-0002-4484-6644. E-mail: julianadavilag@gmail.com. 


\section{Introducción}

En la actualidad Colombia tiene 45 centros históricos, cada uno de los cuales ha sido declarado Bien de Interés Cultural [BIC] del ámbito nacional teniendo en cuenta su relevancia para comprender cómo se han plasmado en el espacio físico el proceso de conquista y colonización hispánica del territorio, traducido en el trazado urbano y la disposición de sus elementos arquitectónicos. Se trata de la máxima categoría de protección que existe en el país para este tipo de patrimonio cultural inmueble $y$, actuando de manera consecuente, atendiendo a la necesidad de protección y conservación de sus principales valores; desde el año 2009 la legislación ha dispuesto la implementación de instrumentos normativos de obligatoria aplicación para tal fin. De esta manera, se ha establecido la necesidad de la elaboración de Planes Especiales de Manejo y Protección [PEMP] para cada uno de ellos. Villa de Leyva, fundada en 1572, es uno de esos centros históricos. Localizada a aproximadamente 160 Kilómetros al noreste de Bogotá y a 40 Kilómetros de Tunja, capital del departamento de Boyacá (ver Figura 1). Este municipio, se ha convertido desde hace aproximadamente tres décadas, en destino turístico del centro del país en buena parte gracias a los valores ligados al patrimonio cultural inmueble, representados en un lenguaje arquitectónico homogéneo propio del periodo colonial que ha derivado en un estilo propio y en un trazado urbano que materializa las directrices que para el caso determinaba la corona española. El renombre que ha adquirido en los últimos años se ve reflejado entre otras cosas en un notorio aumento de la población residente, que según datos de diversos censos de población llevados a cabo por el gobierno colombiano rondaba los 6.000 habitantes en 1985, pero que para el año 2020 se espera que esté cerca de las 20.000 personas, con más del $60 \%$ de ellas ocupando el casco urbano, aunque no necesariamente la zona antigua que ha sido declarada. Lo anterior, de acuerdo con información del Departamento Nacional de Estadística [DANE] (2011).

Figura 1 - Localización de Villa de Leyva en Colombia

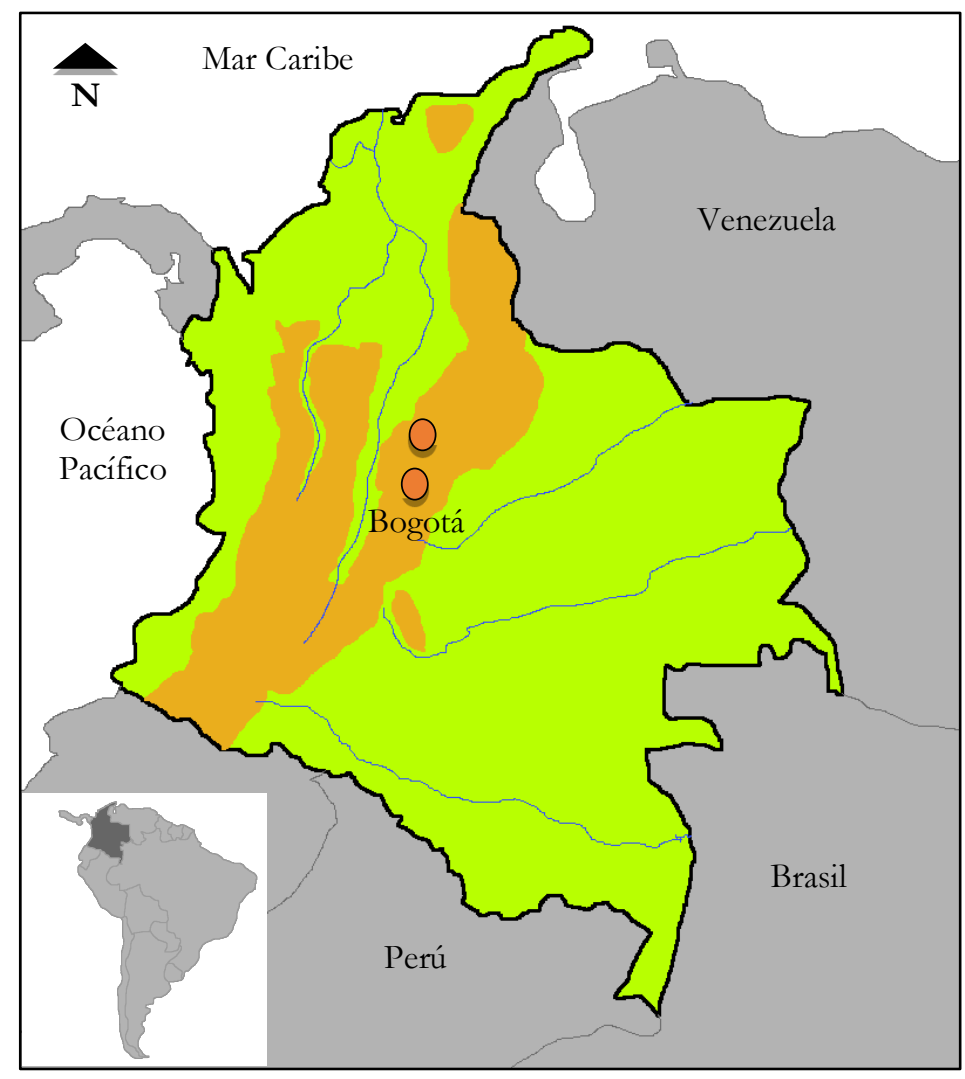

Fuente: elaboración propia, 2020. 
Al lado de Cartagena y de poblaciones como Honda (Tolima) o Barichara (Santander), se podría decir que Villa de Leyva ha sido víctima de su éxito como centro histórico conservado durante varios siglos, debido en parte a su inicial condición de aislamiento con respecto a los ejes viales más importantes del centro del Colombia. Sin embargo, de unas décadas para acá su cercanía con la capital del país ha facilitado la aparición y arremetida tanto del fenómeno de la turistificación como del fenómeno de la gentrificación, lo cual ha desembocado en la salida progresiva de los habitantes tradicionales de la zona antigua a cambio del arribo de personas que llegan buscando los beneficios de las particulares cualidades de este lugar, tales como su temperatura agradable, una arquitectura homogénea y diversidad de paisajes en el entorno inmediato, pero que no necesariamente habitan allí de tiempo completo. Se trata entonces de un centro histórico que la mayor parte del tiempo se aprecia vacío, sobre todo en la zona nororiental, y que en la actualidad conserva pocos elementos del significado cultural que tuvo alguna vez para la población local.

De manera paralela, el casco urbano se expande al ritmo del movimiento de los pobladores tradicionales con todas sus prácticas culturales hacia la periferia (ver Figura 2) y al ritmo de la dinámica económica estimulada por los operadores turísticos e inmobiliarios, que conocedores de las bondades del lugar previamente mencionadas contribuyen con la expansión de la mancha urbana hacia el área rural, a pesar de la histórica carencia de agua en la región y estimulados además por la escasa capacidad operativa de una administración pública que no alcanza a ejercer un control efectivo sobre los propietarios, quienes en algunos casos realizan intervenciones irregulares sobre la arquitectura característica de la población, poniendo en evidencia que el patrimonio inmueble del centro histórico se encuentra en un alto grado de vulnerabilidad.

Esta renombrada vocación turística de Villa de Leyva genera la afluencia masiva de visitantes en ciertas épocas del año, ocasiones en las cuales se pone a prueba la infraestructura del centro histórico, sometido a los riesgos que trae consigo el turismo de masas pero que sin embargo se convierte para muchos habitantes del municipio y de la región en escenario que brinda la oportunidad de obtener ingresos económicos. Es en este punto en donde surge el conflicto entre la protección del patrimonio cultural inmueble y la actividad que en las últimas décadas le ha dado reconocimiento a la población.

Figura 2 - Vista general del casco urbano de Villa de Leyva desde el cerro de Morro Negro

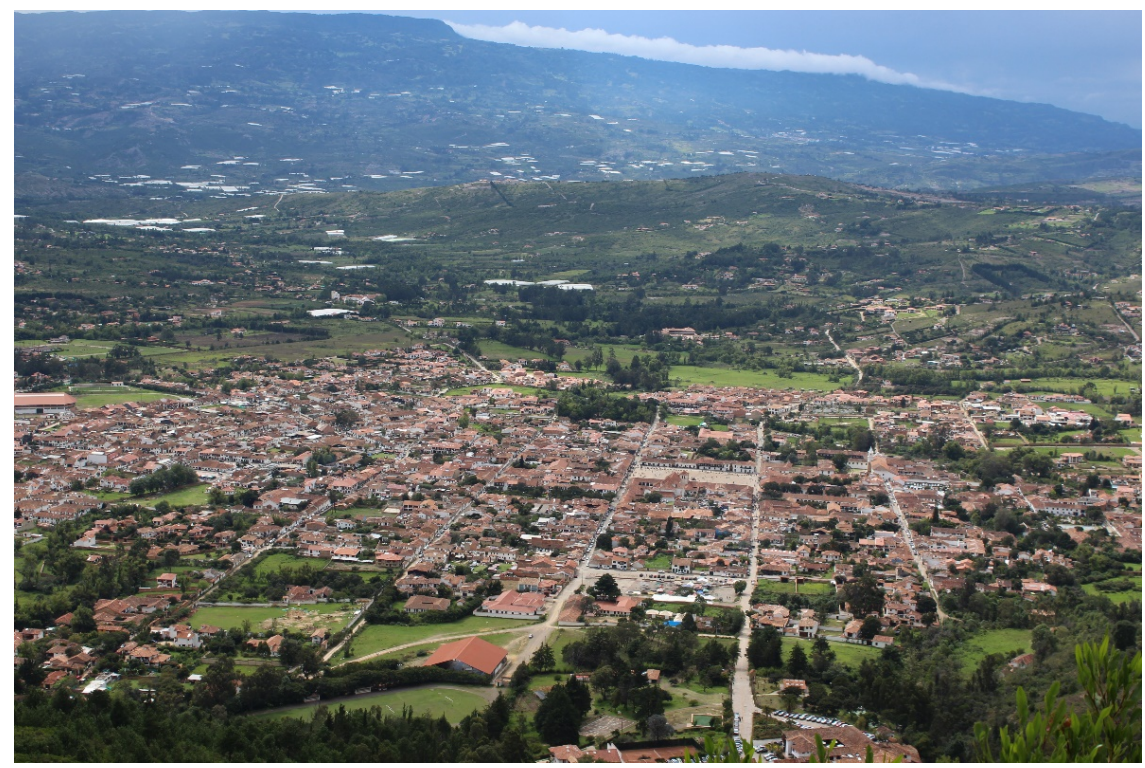

Fuente: Yarleys Pulgarín (2019). 
En más de una ocasión grupos de habitantes, conocedores de la importancia histórica de este lugar y de la importancia de que el manejo de las actividades comerciales en el centro histórico aún esté en sus manos, han logrado detener proyectos de reconocidas empresas del ámbito nacional que implicarían la llegada de grandes operadores foráneos, que ante la fragilidad institucional en un momento dado podrían adquirir poder de decisión sobre el manejo del patrimonio cultural inmueble. Sin embargo, ante el poder de persuasión de los grandes capitales, no se descarta que ello pueda ocurrir en un futuro próximo.

Si bien la formulación e implementación de los PEMP, como instrumento normativo de jerarquía superior dentro del ordenamiento territorial colombiano, pretende proteger los centros históricos de los riesgos a los que se encuentran expuestos y regular las actividades que puedan amenazar su integridad; en el caso de Villa de Leyva existen factores que han retardado su formulación (la cual comenzó desde el año 2011) y aprobación y que por ende han impedido su implementación, comenzando por la carente armonización con otros instrumentos de gestión como los Planes Básicos de Ordenamiento Territorial [PBOT]. Mientras tanto, tienen lugar en este escenario físico dinámicas que de la mano de la turistificación y de la gentrificación poco a poco van minando los valores que en su momento le dieron la denominación de patrimonio cultural inmueble del ámbito nacional.

El presente texto tiene como objetivo principal plantear una reflexión, que se antoja pertinente, teniendo en cuenta la promoción de la actividad turística y de la economía naranja por parte de distintos entes gubernamentales que las presentan como oportunidad viable para comunidades empobrecidas a causa de problemas económicos estructurales, que no encuentran otras posibilidades de ingresos igualmente rentables y que finalmente podrían obtener como resultado el deterioro de sus elementos identitarios, en este caso, su patrimonio cultural inmueble, si no cuentan con la suficiente preparación. Se asoma, sin embargo, como se verá al final, una pequeña luz de esperanza en el empoderamiento de comunidades como la de este caso de estudio y que puede servir como referente para otros centros históricos que puedan estar en una situación similar, más importante si se tiene en cuenta lo planteado en una de las metas del Objetivo de Desarrollo Sostenible [ODS], 11: Ciudades y comunidades sostenibles - Redoblar los esfuerzos para proteger y salvaguardar el patrimonio cultural y natural del mundo (ONU, 2015).

Cumplir con el mencionado objetivo principal requiere exponer las situaciones $y$ dinámicas que han moldeado el centro histórico de Villa de Leyva hasta la forma que tiene en la actualidad, razón por la cual es necesario hablar de su devenir histórico y abordar conceptos como turistificación y gentrificación, los cuales resultan útiles para explicar algunos de los fenómenos que amenazan la pervivencia de los valores patrimoniales de este escenario, así como hablar de las herramientas que ha venido implementando la legislación colombiana dirigidas a la protección de dichos valores, tales como los PEMP.

Al final el presente texto pretende dar luces acerca de una posible ruta a seguir, y se nutre del trabajo de campo realizado a lo largo de los años por parte de las autoras en distintos proyectos y de la participación en el proceso de formulación del PEMP de este centro histórico, puesto que la situación actual de Villa de Leyva lanza una advertencia sobre lo que puede ser el futuro de otros tantos centros históricos para los cuales la armonización de las actividades económicas que dan sustento a los habitantes con la preservación de los valores patrimoniales resulta urgente para garantizar la conservación de los elementos que en su momento motivaron su declaratoria como patrimonio de la Nación.

\section{Metodología}

La aproximación al centro histórico de Villa de Leyva, se ha dado por medio de diversos proyectos de investigación, que se han realizado a lo largo de aproximadamente una década. En primer lugar, la elaboración en el año 2010 de la Lista Indicativa de Patrimonio Cultural de Colombia para la Organización de las Naciones Unidas para la Educación, la Ciencia y la Cultura [Unesco]; proyecto adelantado por la Fundación Erigaie que abarcaba nueve municipios del departamento de Boyacá entre los cuales se encontraba incluido Villa de Leyva, y que implicó entre otras actividades la visita a este centro histórico durante los distintos festivales y fiestas, con el fin de lograr su caracterización con miras a determinar las afectaciones de la actividad turística sobre el patrimonio cultural empleando herramientas como la observación participante, la toma de fotografías y el diálogo con habitantes del municipio; en segundo lugar, la participación en las 
fases de valoración y diagnóstico de este centro poblado como insumo del PEMP, fases durante las cuales nuevamente se visitó la población, se contribuyó en la construcción de la caracterización histórica consultando fuentes primarias de archivo y bibliografía existente, se elaboraron cartografías y se tuvo la oportunidad de intervenir en mesas de trabajo temáticas en las que se interactuó con los pobladores.

Una nueva aproximación a Villa de Leyva se desarrolló durante la elaboración del expediente de nominación de la Subregión de Ricaurte Alto e Iguaque para su inclusión en la lista de Patrimonio de la Humanidad de la Unesco (2012-2014), proyecto también desarrollado por la Fundación Erigaie que en algunas de sus fases requirió de jornadas de socialización y retroalimentación con la comunidad en el diagnóstico de distintas problemáticas, y finalmente la elaboración de la tesis doctoral Memoria, Espacialidad y Culturas Constructivas: La Vivienda Vernácula de la Subregión de Ricaurte Alto e Iguaque (Pulgarín, 2018), durante la cual se hizo énfasis en el estudio del territorio tomando como punto de partida algunos de los postulados propios de la fenomenología.

Durante el año 2019 se hizo necesaria la actualización del documento de formulación del PEMP para su aprobación por parte del Ministerio de Cultura, con base en las observaciones realizadas por la comunidad al documento inicialmente culminado en el año 2017. Este proceso tuvo una duración de tres meses y en las sucesivas visitas que se hicieron se tuvo la oportunidad de hacer una comparación entre la situación del centro histórico en el año 2011, con la que se apreciaba en ese momento, haciéndose evidente la necesidad de la adopción de este instrumento normativo con el fin de mitigar los efectos que la actividad turística y la gentrificación han tenido sobre este BIC del ámbito nacional. En su momento, las conclusiones de este ejercicio alimentaron las discusiones académicas que durante este mismo año se adelantaron en distintos espacios académicos en el programa de Arquitectura de la Facultad de Ciencias del Hábitat, que tomaron como escenario de trabajo el centro histórico de Villa de Leyva.

$\mathrm{Si}$ bien algunos de los proyectos de investigación antes mencionados no se concentraron en la explicación de algún fenómeno puntual del lugar de estudio que aquí se presenta (como el caso del proyecto de la elaboración del expediente de nominación ante la Unesco), su ubicación privilegiada en la región lo convirtieron en centro de operaciones, lo cual implicó permanecer allí durante varias semanas, interactuar con pobladores y apreciar sus distintas dinámicas en diversos momentos del año. La aproximación a conceptos relacionados con el turismo enunciados por Bertoncello (2006), Hiernaux y González (2014), la gentrificación (Smith, 1996; Hiernaux y González, 2014) e incluso las heterotopías patrimoniales de Costa y Alvarado-Sizzo (2019), resultaron útiles para la comprensión de la problemática ligada a la invisibilización de los valores patrimoniales, bajo la utopía que crea imaginarios y guía la experimentación del lugar por parte del visitante. El presente texto se muestra entonces como la conclusión de un trabajo realizado a lo largo de casi una década de la historia del municipio marcada por el desarrollo del PEMP, proceso del cual ha estado enterada y ha sido partícipe una parte de la población residente y del que al final se pueden extraer valiosas conclusiones de cara a su eventual aprobación e implementación en el corto plazo, no sólo en el ámbito local sino también para otras poblaciones que puedan estar pasando por un proceso similar.

\section{Contexto ambiental y demográfico}

El casco urbano de Villa de Leyva se encuentra localizado a 2.200 m.s.n.m., sobre el ramal oriental de la cordillera de Los Andes y a aproximadamente 40 kilómetros al oriente de Tunja, la capital del departamento de Boyacá, en un enclave seco que durante el periodo cretáceo estaba cubierto por un mar interior, que ha dejado como testimonio de su pasado un amplio potencial paleontológico, reflejado en el hallazgo periódico de fósiles de fauna marina, tal y como lo mencionan Ariza (1972) y Molano (1994). Por otra parte, la población cuenta en la actualidad con aproximadamente 20.000 habitantes, la mitad de los cuales se concentra en el casco urbano. Esta situación lo convierte en el municipio más importante de la zona, y en ese sentido cumple con una importante función como nodo de actividades administrativas y comerciales para toda la subregión, que abarca un total de siete municipios.

Llama la atención la condición de Villa de Leyva de cabecera de la zona, aunque el casco urbano se encuentra separado de las vías principales de acceso de la región, como la que conecta a Bogotá con el nororiente del país y la que comunica a Tunja con el occidente del 
departamento, hecho al cual ha contribuido el haberse convertido en destino turístico y por lo tanto en la población más conocida de la zona desde hace tres décadas para quienes habitan el interior del país como producto de un esfuerzo del Estado por promover el turismo doméstico, como se verá más adelante.

Como es de esperar, el auge de dicha actividad turística ha incidido en el aumento del número de habitantes del municipio y la ampliación de la mancha urbana. Es así como se tiene información que establece que en 1871 (año en el que se obtuvieron los primeros datos de censos oficiales) Villa de Leyva contaba con 3.045 pobladores, en 1951 (antes de la declaratoria del caso urbano como "Monumento Nacional") con 4.112, en 1993 con 7.333, en 2005 con 14.125 (para este año ya el $10.7 \%$ de los habitantes residía en el municipio hacía menos de cinco años) y en 2014 con 15.983, mientras que para el año 2020 se proyecta una población total de 19.171 (DANE, 2011), convirtiéndose así en la entidad con mayor crecimiento de la región.

\section{De villa española a destino turístico}

El casco urbano de Villa de Leyva se localiza en lo que fueran los dominios de un territorio indígena independiente, por el cual pasaron las huestes de Gonzalo Jiménez de Quesada en 1537 en su camino desde la costa norte hacia el centro del país, para posteriormente fundar la ciudad de Bogotá (Ariza, 1972). Exentos del dominio de los más importantes gobernantes muiscas, los grupos que aquí habitaron se caracterizaron por su dependencia únicamente de un jefe local con poder limitado. Investigaciones que se han realizado en la región muestran un patrón de ocupación disperso del territorio con unos pocos núcleos en donde se localizó una mayor cantidad de población indígena en un periodo próximo a la llegada de los españoles en las áreas fértiles y planas cerca de los mayores cursos de agua, pero nunca en la zona en la que posteriormente se localizaría Villa de Leyva (Langebaek, 2000). Se estima que para este momento el número de habitantes llegaba en total a 6.000 personas, cantidad relativamente pequeña si se compara con otras áreas del centro del país (Langebaek, 2000).

Dentro del proceso de conquista adelantado por los españoles en el interior del territorio de lo que hoy es Colombia y en relación directa con el caso de estudio aquí presentado, dos fechas merecen ser destacadas. En primer lugar 1539, cuando es fundada Tunja, la capital del departamento de Boyacá, y 1572, cuando Hernán Suárez de Villalobos funda la villa por instrucción del presidente en ese entonces, Andrés Díaz Venero de Leyva, y a la que estarán destinadas las personas que en ese momento no tenían tierras en la mencionada capital y en la ciudad de Vélez (Ariza, 1972). Con un mejor acceso al agua que en la capital gracias al hecho de encontrarse en medio de dos ríos (San Francisco y San Agustín), la existencia de molinos de trigo, un clima benévolo que recordaba a los pobladores el de la península ibérica y una posición de dominio sobre los poblados indígenas en medio de los cuales se localizaba, el actual centro histórico se convirtió en sede de la administración de la pequeña zona, pero llegó a disputar ante la corona el privilegio de ostentar la categoría de ciudad, rivalizando con Tunja (Ariza, 1972).

La pronta llegada de diversas órdenes religiosas (franciscanos, agustinos, mercedarios, concepcionistas) en un territorio relativamente pequeño que obtendría renombre gracias a la calidad de la harina que producían los molinos de trigo, atrajo un aparente progreso a la región que termina de manera abrupta cuando tras un eclipse de sol en 1691 una plaga cae sobre los cultivos (Ariza, 1972) y al comenzar la decadencia la pequeña población comienza a ser abandonada. Sin embargo, la producción de trigo se mantuvo hasta hace pocas décadas, aunque ya no con la pujanza que le caracterizó al comienzo y pequeña en comparación con la de otros municipios de la región.

Posteriormente, Villa de Leyva aparece en la historia nacional de manera puntual en cuatro momentos. En primer lugar, con el paso del movimiento de los comuneros en 1781 que constituyó un importante precedente del movimiento independentista que finalmente se cristalizó en 1810 (Ariza, 1972); en 1812 cuando se convierte en sede del Congreso de las Provincias Unidas, que buscaba generar acuerdos para la administración del territorio recientemente independizado (Contraloría General de la República, 1936) y en 1816 cuando son asesinados algunos pobladores locales en el marco de la reconquista del territorio por parte de la corona española, conocido como el Régimen del Terror (Ariza, 1972). Finalmente, a mediados del siglo XIX pasa por la zona la expedición corográfica, proyecto emprendido por la administración del 
entonces presidente José Hilario López con el fin de ampliar los conocimientos sobre los territorios que conformaban en ese entonces la naciente república (Ancízar, 1956). En este momento, el autor menciona que

La Villa se compone de un número razonable de casas de teja mal construidas y peor amuebladas, en que se albergan cerca de 2.000 babitantes (...). Vivese alli en la quietud y recogimiento peculiares de las poblaciones españolas y correspondiente a la falta de comercio y quehaceres activos, en tales términos que ni aun las autoridades cantonales se hallaban en el silencioso pueblo cuando llegamos (...). El cantón, no obstante su decadencia, sostiene un regular comercio doméstico, cuyas contrataciones se hacen en los mercados semanales (Ancízar, 1956, p. 307).
Alejada de las principales vías de comunicación terrestre, férrea, fluvial y aérea, Villa de Leyva permanecería en el letargo por aproximadamente un siglo, cuando en el año 1954 el casco urbano es declarado Monumento Nacional, denominación que, a partir de la promulgación de la Ley General de Cultura de 1997, cambió a la de Bien de Interés Cultural del ámbito nacional y que actualmente comparte con otros 44 centros históricos en Colombia. Entre las características urbano arquitectónicas destacadas en su momento se encuentran el trazado en damero localizado en el piedemonte del cerro conocido como Morro Negro y los paramentos continuos de sus calles, delimitadas por una arquitectura de tierra construida en su momento con técnicas tradicionales (tapia pisada y bahareque) que se complementaba con el uso de carpinterías en madera y cubiertas inclinadas en teja de barro.

Figura 3 - Crecimiento del trazado urbano de Villa de Leyva a lo largo de los años

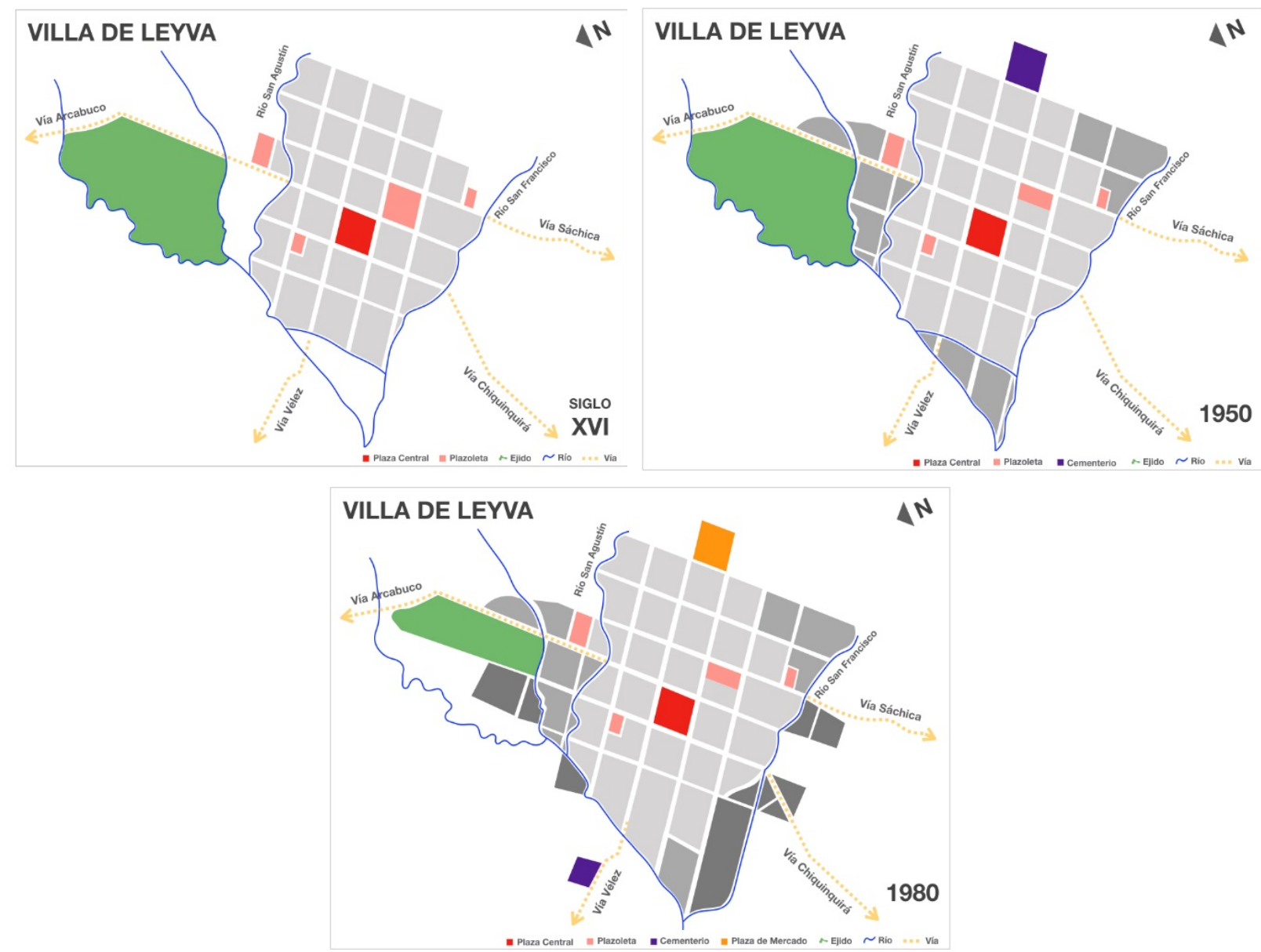

Fuente: Juliana Dávila (2019). 
A partir de 1968, se han realizado diferentes estudios enfocados en la conservación del patrimonio urbano y arquitectónico, al final de los cuales se expidieron los Acuerdos Municipales 004 de 1989 (Concejo Municipal de Villa de Leyva, 1989) y 007 de 1996 (Concejo Municipal de Villa de Leyva, 1996), siendo este último el que constituye en la actualidad la reglamentación vigente para el centro histórico de Villa de Leyva. Años más tarde, la Ley 397 de 1997, primera Ley General de Cultura de Colombia (República de Colombia, 1997), fue modificada por la Ley 1185 de 2008 (República de Colombia, 2008), y en ella se incluyó la figura del Plan Especial de Manejo y Protección, PEMP, como "instrumento de gestión del patrimonio cultural por medio del cual se establecen las acciones necesarias para garantizar su protección y sostenibilidad en el tiempo." Posteriormente, en 2011, el municipio de Villa de Leyva emprendió el proceso de elaboración del PEMP, el cual a la fecha preliminarmente ya fue aprobado, pero aún no ha sido implementado por parte de las autoridades competentes.

El estudio de las aerofotografías históricas de este casco urbano deja ver en el momento de la declaratoria apenas un puñado de edificaciones cuyo número no sufrió grandes alteraciones hasta los años 90 (ver Figura 3). Tan sólo unas pocas décadas después de alcanzada su declaratoria como BIC, Villa de Leyva ha alcanzado reconocimiento por la presencia de valores asociados con el patrimonio cultural inmueble, a la par con el creciente número de visitantes que han llegado atraídos por las actividades culturales y turísticas que allí se realizan desde mediados de los años 70 y de este modo, se ha convertido en un destino de descanso y recreación para nacionales y extranjeros, situación que ha impulsado su crecimiento demográfico y su desarrollo urbano.

\section{Dinámicas actuales del centro histórico de Villa de Leyva}

El considerable aumento del número de habitantes del área urbana de Villa de Leyva, representado en buena parte en personas provenientes de otras zonas que llegaron motivadas inicialmente por el deseo de disfrutar de sus valores estéticos, espirituales y ambientales, sumado al posterior crecimiento en la cantidad de visitantes que acuden cada fin de semana desde el centro del país como producto de su consolidación como destino de ocio, ha implicado un aumento en la presión sobre la estructura urbana del municipio y en especial del centro histórico. Ello es más notorio en las fechas en las que se celebran los festivales más reconocidos (de cometas en agosto y de luces en diciembre), cuando según datos suministrados de manera oral por funcionarios de la alcaldía municipal pueden llegar aproximadamente 20.000 personas al casco urbano en un solo día, y se pueden observar filas de hasta cinco kilómetros de longitud de vehículos que pretenden ingresar a la población.

Villa de Leyva tiene además una condición de nodo de actividades y de servicios de la provincia de Ricaurte Alto, lo que implica la atención a personas que acuden desde los municipios vecinos (Sáchica, Santa Sofía y Gachantivá) a realizar trámites de diverso tipo diariamente, pero que sin embargo no afecta la funcionalidad de la estructura urbana de manera tan notoria como en los festivales mencionados previamente.

Este creciente interés sobre Villa de Leyva también repercute en una considerable presión inmobiliaria sobre las áreas suburbanas, pues viene siendo colonizada por iniciativas que compiten en calidad y precio con los bienes y servicios ofrecidos en el casco urbano, así como también se aprecia la densificación del área urbana y particularmente del centro histórico, entre otras dinámicas que se abordarán más adelante y que como se verá ponen en riesgo la conservación de los valores de este espacio como entorno patrimonial.

\subsection{Turismo: ¿ventaja o desventaja?}

El principal activo turístico del centro histórico de Villa de Leyva es su condición patrimonial, pues es la materia prima que le impulsa y del cual se nutre (Bertoncello, 2006). Pero no se trata de un reconocimiento accidental, sino que resulta de un proceso que es fruto del interés de diversos actores en ello (Bertoncello, 2006). Si bien dicho interés recaía inicialmente y casi que de forma exclusiva en la población local, de forma similar a lo ocurrido en otros países de la región a finales del siglo XX (Bertoncello, 2006) la promoción del turismo doméstico toma un impulso decisivo por medio de una campaña presentada por la Corporación Nacional de Turismo (creada en 1968 y hoy denominada Fondo Nacional del Turismo - Fontur) en la que se buscaba la alianza con empresarios del sector privado desde la década de los noventa, y contribuye a definir el perfil de este centro histórico en tanto los eventos otrora familiares que congregaban especialmente a la comunidad residente ahora se presentan como eventos de gran formato que buscaban atraer público foráneo. 
Según lo afirma Bertoncello (2016), la actividad turística establece de inmediato una relación entre el visitante y el visitado en la que de paso se refuerzan elementos de identificación y distinción social, sobre todo cuando el valor económico de los bienes y servicios del lugar de destino dificulta el disfrute de los valores patrimoniales representativos por parte de personas con ingresos bajos aún hoy (Bertoncello, 2006). Es lógica la predilección por Villa de Leyva sobre otros destinos turísticos, en tanto en un país como Colombia, con una topografía compleja y una situación de seguridad predeterminada por la existencia de un conflicto armado en amplias zonas, tener cerca de la capital una población tranquila a la que se puede llegar en menos de tres horas en automóvil, en medio de un paisaje con notorios atributos estéticos y con un clima agradable, constituye una ventaja y un factor diferenciador con respecto a los destinos tipo balneario del centro del país.

El proceso de valoración patrimonial de ya no sólo las riquezas culturales sino también naturales de la región no ha hecho más que llamar la atención de cada vez más visitantes: De una actividad turística contemplativa y cultural concentrada en el centro histórico que por medio de dispositivos como los museos permitía una lectura del devenir histórico del país desde este territorio, se ha pasado al turismo de aventura, el cual tiene como nodo de actividades la zona rural y deja a la zona declarada BIC del ámbito nacional como escenario de disputas en tanto el disfrute de lo patrimonial como cualidad añadida es sinónimo de prestigio social entre los visitantes (Bertoncello, 2006) pero a la vez de pugna con y entre los actores locales tradicionales por su dominio, mientras la lectura de la estructura básica de dicha matriz patrimonial pasa a un segundo plano en tanto la mayor parte de la arquitectura que el observador tiene a su alcance no procede del periodo colonial, pero transmite la ilusión de ser antigua, noción reforzada por la presencia del empedrado que sirve para reconocer la zona declarada:

La prensa de los años 90 da cuenta del tamaño y el impacto que los eventos turísticos ya estaban ocasionando sobre el Bien de Interés Cultural: oleadas de visitantes, basuras, ruido, desorden. En la actualidad el número y la variedad de eventos (astronómico, de música antigua, de cine independiente, del árbol, ferias equinas, diversos conciertos, entre otros) ha aumentado, buscando la llegada de turistas de manera cada vez más recurrente a la población. Es así como de los festivales de cometas (agosto) y de luces (diciembre) se ha pasado a una oferta diseñada para los asiduos visitantes citadinos antes que para los habitantes del propio municipio o de los municipios vecinos. De este modo, durante la realización de estos festivales, el centro histórico se ve desbordado con miles de visitantes que expulsan a los habitantes del municipio de sus espacios de socialización, lo cual les lleva a buscar otros escenarios para tal fin en los bordes de la población. Impacto similar se aprecia en la zona rural, en donde el cada vez más creciente número de atractivos turísticos y viviendas de recreo ha hecho de Villa de Leyva un municipio con un número de campesinos que tiende a disminuir en comparación con los municipios vecinos.

El escenario principal de los eventos es la plaza mayor, el espacio en el que es más notorio el impacto de la actividad turística, y los espacios

Figura 4 - Comparativo de la plaza mayor de Villa de Leyva en un día sin afluencia de público vs. un día de festival de cometas. A la izquierda se aprecia el cerro de Morro Negro como telón de fondo
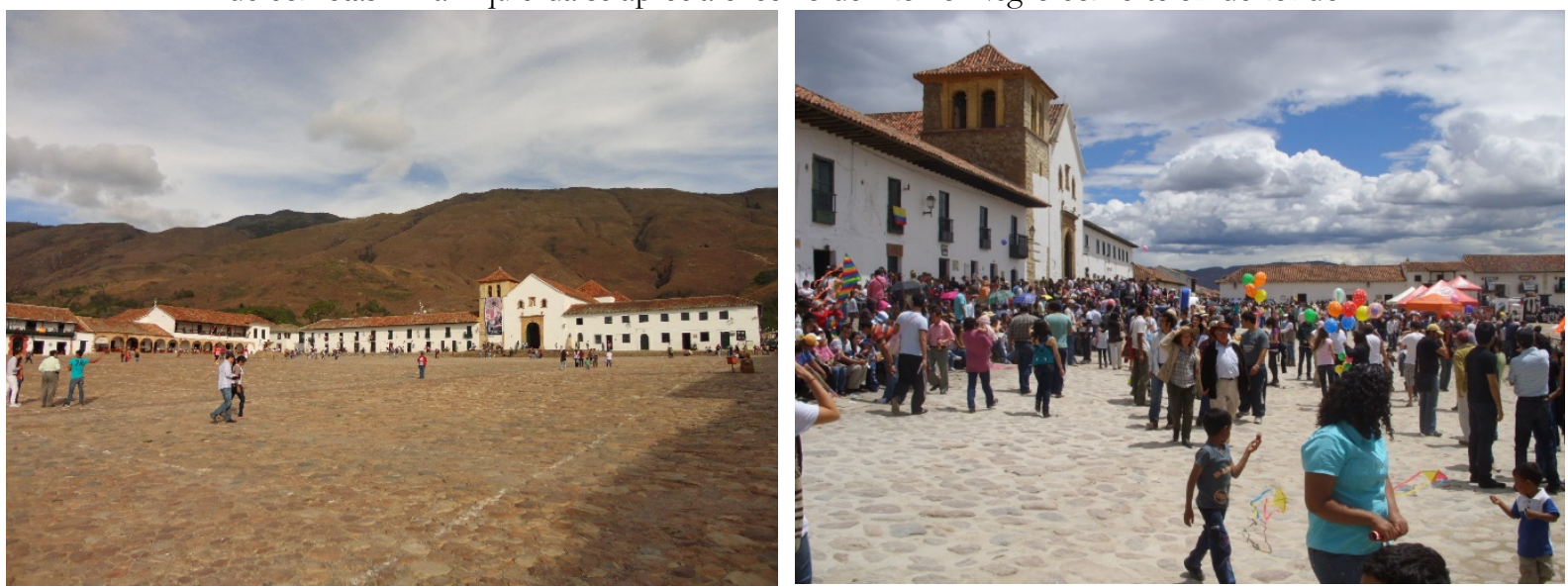

Fuente: Yarleys Pulgarín (2011). 
comerciales localizados en su contorno son los que más se han transformado con dicha dinámica, generando recintos ocupados generalmente por los turistas según lo mencionado por Hiernaux y González (2014), como se verá más adelante (ver Figura 4).

El auge de visitantes durante todo el año ha convertido este entorno patrimonial en la mente de muchos habitantes de la región en una fuente de empleo. A este imaginario contribuyen las difíciles condiciones económicas ligadas a la actividad agropecuaria en el país (Fals, 1973), que expulsa campesinos de manera permanente hacia los centros urbanos y por lo tanto hacen de Villa de Leyva un lugar para buscar oportunidades laborales. Es así como mientras en los municipios vecinos la producción de alimentos se ha reducido de manera drástica (Pulgarín, 2018), los adultos migran a lugares como este centro histórico buscando un lugar donde poder ubicarse laboralmente en alguno de los tres sectores con más movimiento: turismo, comercio y construcción.

Antes de la aparición de eventos de gran formato Villa de Leyva se destacaba por contar con siete museos (algunas de cuyas colecciones están en mora de ser renovadas) que exaltan la historia y el patrimonio paleontológico de la región, y era reconocida además por haber sido lugar de residencia de destacadas personalidades y artistas que hicieron que Villa de Leyva descollara en la escena cultural del país. La presencia de este tipo de equipamientos sigue atrayendo visitantes todo el año, y aunque no constituyen un estímulo suficientemente poderoso como para atraer grandes cantidades de público foráneo, se escuchan cada vez más voces de habitantes y académicos que defienden la posibilidad de un turismo que respete los valores del patrimonio cultural inmueble como uno de los principales atractivos del municipio en el ámbito nacional. Alcanzar este propósito implica, sin embargo, medir capacidades de carga, capacitar operadores y mejorar la infraestructura, entre otras acciones que se enmarcan en un Plan de Desarrollo Turístico que a la fecha no se ha diseñado y que representa un alto costo para la administración local.

Este auge de la actividad turística sin control, que lleva un número cada vez mayor de visitantes al centro histórico de Villa de Leyva, que no siempre son conscientes de la existencia de valores patrimoniales en este escenario, se ha traducido también en la pérdida de espacios para la escenificación de las prácticas culturales de los habitantes del municipio, especialmente las fiestas de carácter religioso. Entre todas ellas, sobrevive como la más importante: la de la Virgen del Carmen; devoción religiosa más importante de la población, que tiene lugar en el mes de julio durante la cual miles de campesinos y comerciantes de la región ocupan el poblado durante unos pocos días, en los que el flujo de turistas se ve disminuido y la actividad comercial disminuye, en lo que parece ser un acto de resistencia, de autoafirmación de la identidad y de recuperación del espacio por parte de quienes allí residen ante el embate del turismo de masas.

El auge de esta actividad turística ha derivado en dos fenómenos que serán descritos a continuación: la gentrificación y la turistificación.

\subsection{Gentrificación y turistificación, y sus múltiples efectos}

En su acepción más conocida, el concepto de gentrificación hace referencia, en resumen, al proceso de ocupación de los barrios céntricos deteriorados de las grandes urbes, por parte de nuevos habitantes de otra extracción social, usualmente de estratos medio alto o alto; según el término acuñado en 1964 por la socióloga Ruth Glass (Smith, 1996). De este modo, con el paso del tiempo los habitantes tradicionales de estos lugares terminan por ser expulsados debido el aumento en el valor del suelo y en el costo de vida (Vásquez, 1996). Según Smith (1996), la gentrificación es el proceso "por el que los barrios pobres y proletarios, ubicados en el centro de la ciudad, son reformados a partir de la entrada del capital privado y de compradores de viviendas e inquilinos de clase media", cargado con una connotación clasista negativa por estar relacionado con el desplazamiento de habitantes y que ya a comienzos de los años 60 era evidente en varias ciudades. De acuerdo con el autor, dicho proceso de reemplazo no siempre se encuentra ligado o es producto de la decadencia de las estructuras físicas, sino que más bien responde a dinámicas de uso del espacio diferentes a las que son tradicionales del lugar por parte de los nuevos residentes (muchos de ellos en este caso procedentes de Bogotá), como ocurre con el traslado de patrones de la vida urbana de las grandes ciudades a contextos urbanos de pequeño formato, como en el caso de Villa de Leyva.

Como tal, la gentrificación también se observa en las capitales latinoamericanas y en lo que respecta a este caso de estudio, en centros urbanos pequeños que tienen un carga histórica importante; se ve reflejada no sólo en el desplazamiento de la población raizal sino también en la adopción de nuevas materialidades y formas de usar el espacio, que terminan por verse 
descontextualizadas del tejido urbano en el cual se implantan aunque moviéndose en los difusos márgenes de la normativa urbana vigente.

El caso de la turistificación es similar, pero la diferencia radica en los nuevos actores involucrados; los pobladores de los barrios son desplazados por los turistas, pues el comercio y los servicios se centran en satisfacer las necesidades de este tipo de visitantes (Rodríguez, Cota, Salguero y García-García, (2018). Una postura con más amplios alcances es exhibida por Hiernaux y González (2014, p.58), quienes consideran en la existencia de patrimonio cultural uno de los principales motivos por los cuales existe la actividad turística en áreas urbanas, siendo ésta un detonante para su crecimiento a la vez que facilitador de la existencia de un grupo social económicamente privilegiado vinculado a ello, estableciendo de paso una relación con la gentrificación que se explica en que "no es solamente un cambio en las actividades o los residentes (vistos como grupo, o sea, genéricamente, los 'turistas') sino también la producción de un conjunto de interacciones entre turistas y residentes permanentes que opera no solo en el plano material sino también y quizás sobre todo, en el plano simbólico", y considerando al turista un tipo de habitante más (aunque de carácter abstracto) con sus propias prácticas y formas de usar el espacio.

Ante la ausencia en Villa de Leyva de una operación urbana de gran escala promovida por el Estado que haya facilitado el proceso de la gentrificación, más allá de la existencia de una normativa que ha estandarizado las reglas de juego para los distintos actores interesados en la actividad turística y pequeñas inversiones para el mantenimiento y restauración de algunos inmuebles de carácter público y del propio espacio colectivo que pretende mantener una imagen prístina del glorioso pasado del centro histórico, para Hiernaux y González (2014) el turista opera como habitante pero no residente permanente y sin embargo se ha convertido en un factor que ha promovido dicho fenómeno en tanto como individuo categorizado bajo una condición genérica es capaz de producir y reproducir el espacio, sea de manera física o simbólica, a cuyas demandas están atentos los operadores turísticos a la vez que determinan lo que el visitante debe ver o conocer (Hiernaux y González, 2014).

En el caso de Villa de Leyva, es difícil definir cuál de estos dos fenómenos es el de mayor incidencia en su centro histórico, pues a pesar de no tener punto de comparación con lo ocurrido en las grandes urbes que dio origen a estos conceptos en Europa; lo cierto es que, en los últimos 30 años, se han sucedido de distintas formas diversas situaciones asociadas a los dos fenómenos. Como se puede apreciar en la postura de Hiernaux y González (2014), tienen vasos comunicantes entre sí. Así, es posible señalar que tanto el área urbana como el área declarada como BIC nacional han tenido un desarrollo inmobiliario inusitado, en el cual han ido quedando al margen los habitantes locales. Los lugares apropiados por los turistas constituyen lo que los autores Hiernaux y González (2014) han definido como recintos, espacios de conflicto con los habitantes locales en vías de gentrificación que tiene rasgos particulares por no ser promovida por una clase pudiente sino por parte de los visitantes.

Esta dinámica es evidente en el número creciente de inmobiliarias y comercios que venden materiales de construcción, así como en la cantidad de edificaciones que permanecen vacías en algunas zonas del área declarada, en intervenciones realizadas en inmuebles localizados en este espacio o al interior de predios antes vacíos, y en el crecimiento del área construida en la periferia del casco urbano, lugar donde han ido a parar muchos de los otrora habitantes de la zona declarada con sus prácticas culturales.

El fenómeno de la gentrificación se hace presente también en el ámbito rural de manera cada vez más notoria, pues es evidente la presión inmobiliaria en tanto ha venido reemplazando las parcelas antes dedicadas a las actividades agropecuarias por espacios residenciales que son ocupados de manera temporal, usualmente los fines de semana y en temporada de vacaciones. En ambas situaciones se aprecia la presencia de un actor predominante, los grupos de visitantes con cierto nivel de poder adquisitivo.

La turistificación, ese "complejo proceso que precisa de un tejido fino de políticas y acciones concretas" que "constituye lo que ha sido denominado por Knafou y otros la "puesta en turismo" (Hiernaux y González, 2014, p. 62) que se traduce en el reemplazo de los antaño tradicionales lugares de interacción comercial por tiendas de moda en donde se venden productos importados o a un alto precio y restaurantes en donde la oferta relacionada con la culinaria local es escasa, tiene una importante escenificación en la plaza de mercado como una de las manifestaciones más importantes para el patrimonio inmaterial del municipio como espacio de interacción social y comercial (Martín-Barbero, 2008), en donde aún es posible encontrar vendedores y productos de la región pero los precios usualmente son elevados y están fuera del alcance de buena parte de los 
pobladores del municipio, los raizales, quienes finalmente optan por otras opciones a la hora de abastecerse:

Esta puesta en turismo buscará la producción de un entorno favorable a este posturismo, el cual requiere de una masa significativa de boteles, restaurantes, eventos culturales y galerías de arte y tiendas de objetos representativos, entre otros, los cuales encuentran cabida en el espacio fragmentado y compuesto de estructuras de escalas pequeña o mediana, adaptables a esos usos nuevos y cargados del aura que les atribuye su historicidad: esto explica, entre otros, la boga actual de los "botelesboutiques" ubicados en estructuras arquitectónicas de pequeña escala, impensables en el marco del turismo de masa del capitalismo organizado, pronto a resolver por la gran escala las necesidades de los consumidores pasivos de su época (Hiernaux y González, 2004, p. 62).

Numerosos hoteles, hostales y posadas se localizan en el centro histórico, pero, aunque la oferta es variada e incluye un amplio rango de precios, han tenido que afrontar el surgimiento del fenómeno de la informalidad de manera similar a lo que ocurre en otras ciudades a raíz de la irrupción de plataformas digitales que ofrecen una competencia difícil de afrontar. De este modo, se percibe cómo este espacio, que ha sido por años motivo de orgullo de los villaleyvanos como elemento de reconocimiento a nivel nacional e internacional, ya no les pertenece a sus habitantes originarios sino a quienes están impulsando fenómenos como la turistificación, y por el contrario los habitantes locales se han visto en la necesidad de trasladarse a otros sectores del municipio, e incluso, a otros municipios.

\subsection{Desarrollo inmobiliario, actividad sin control}

El renombre de Villa de Leyva como sitio de descanso, ha incidido en la elección de la población como lugar de segunda residencia de un número creciente de personas que han optado por adquirir propiedades en el área declarada como BIC, aumentando así la demanda de comercio y servicios que ha impulsado a otras tantas a establecer sus negocios en el lugar. De igual manera, su éxito como destino turístico ha representado el crecimiento en el número de hoteles y viviendas de alquiler por temporadas. De este modo, es evidente el incremento de la actividad inmobiliaria, lo cual ha generado una necesidad de aumento de la vigilancia y el control por parte de las autoridades encargadas (actualmente con una capacidad operativa limitada) de las licencias de construcción en el centro histórico y al mismo tiempo, ha promovido la llegada de profesionales que desde su propia óptica individual proponen intervenciones que no siempre resultan respetuosas de los valores que posee este entorno patrimonial. Ello ha implicado poner la lupa de manera constante sobre el instrumento normativo vigente $\mathrm{y}$ la necesidad de su actualización, a saber, el Acuerdo Municipal 007 (Concejo Municipal Villa de Leyva, 1996), así como sobre las autoridades responsables de su implementación.

La valoración patrimonial que en su momento se les otorgó a las características urbano arquitectónicas del centro histórico de Villa de Leyva y las sucesivas normativas que de allí se derivaron, desembocaron de manera inadvertida y según la opinión de algunos investigadores, en la adopción de un acuerdo tácito entre los pobladores y constructores que favoreció la permanencia de un lenguaje arquitectónico homogéneo que buscaba mantener los elementos de las edificaciones más antiguas en aquellas que fueran construidas de ahí en adelante. Se trata por lo tanto de un tipo de conocimiento denominado memoria social que se transforma lentamente $y$ es transmitido de generación en generación de manera predominante entre sociedades rurales o con poco acceso a los registros escritos (Anderson, 1999), con pocos cambios a lo largo del tiempo.

Para el caso de estudio, esta definición se ajusta especialmente a los maestros de obra y a los propios habitantes que durante décadas mantuvieron una manera de construir porque era la única que conocían, en contraste con el caso de los arquitectos que, poseedores de una memoria disciplinar que se caracteriza por el manejo de registros y la consolidación de todo un corpus especializado (Anderson, 1999), han aparecido en escena en los últimos años ante el requerimiento de las autoridades locales de un profesional de este tipo para la expedición de licencias o permisos de construcción.

El impacto que ha tenido la práctica profesional de la arquitectura, complementada por un cuerpo normativo que desestimula el uso de las técnicas tradicionales en tierra en los procesos constructivos, como ocurre por ejemplo con el Reglamento Colombiano de Construcción Sismo Resistente (Ministerio de Ambiente, Vivienda y Desarrollo Territorial, 2010), ha propiciado la aparición de edificaciones que con su expresión formal poco a poco se van desviando del lenguaje tradicional del centro histórico, mutando de 
manera lentamente y configurando un nuevo lenguaje que se repite por doquier y genera evidentes contrastes con la arquitectura preexistente.

Igualmente, durante los más de 20 años transcurridos desde la promulgación del Acuerdo Municipal 006 (Concejo Municipal Villa de Leyva, 1996) hasta hoy, fecha en que aún no existe una normativa actualizada que responda a las nuevas dinámicas del centro histórico, se han evidenciado vacíos que han permitido entre otras cosas, un incremento en los índices de ocupación (entendido como el resultado de dividir el área construida en primer piso sobre el área del predio), lo cual deriva en su densificación, así como otra serie de afectaciones al patrimonio cultural villaleyvano. Una drástica alteración en este sentido tiene impacto no solamente en el ámbito urbano arquitectónico de este escenario sino también en el ambiental, por cuanto los centros de manzana, que contrastan con la paramentación continua de las calles, han sido por mucho tiempo usados como corredores de especies animales y reservorio de semillas y especies vegetales cuya función ecológica podría llegar a verse alterada en el futuro si el área destinada para tal fin disminuye.

\subsection{Interacciones entre grupos locales}

Cuando se interactúa con la población villaleyvana no se puede ignorar la existencia de dos grupos que desde su propia visión han aportado luces que han ayudado a construir una valoración integral del centro histórico. En primer lugar, se encuentra quienes han nacido allí o en los municipios vecinos y por lo tanto han podido ser testigos desde su infancia de los cambios que han ocurrido en la población y en la región a lo largo de los años. En segundo lugar, se encuentran quienes provenientes de otras zonas del país, especialmente Bogotá, han llegado con la intención de radicarse desde hace unas pocas décadas. En ambos grupos hay personas que son conscientes de la importancia de conservar este escenario, pero que sin embargo no habían encontrado motivos para interactuar de una forma decidida en pro de la defensa del patrimonio cultural.

Sin embargo, de unos años para acá, después de iniciados los procesos de elaboración del Plan Especial de Manejo y Protección en 2011 y de elaboración del expediente de nominación de la Subregión de Ricaurte Alto e Iguaque como Patrimonio Mixto de la Humanidad ante la Unesco, entre 2012 y 2015, estos grupos han encontrado en la alianza una estrategia de resistencia ante los cambios que está experimentando el centro histórico y que han puesto en riesgo sus valores patrimoniales, pues unos y otros han encontrado en ello un punto de confluencia. Ha ocurrido previamente con la protesta ante entidades gubernamentales por la propuesta de instalar infraestructura asociada a la producción petrolera en el vecino municipio de Sutamarchán debido al impacto que podía tener este tipo de actividad en la región, y ha ocurrido de manera más reciente al momento de ejercer labores de veeduría y presión ante las administraciones locales por el otorgamiento de licencias de construcción en la zona suburbana del municipio o para exigir dar trámite al proceso de ajuste $\mathrm{y}$ entrega del documento del PEMP al Ministerio de Cultura para su revisión y preliminar aprobación, proceso que se espera esté culminado en 2020.

La comunidad de Villa de Leyva también ha demostrado actuar de manera unida ante la eventual incursión de grandes cadenas comerciales y grupos económicos que han pretendido instalarse en el municipio, lo mismo que ante lo que considera atropellos al patrimonio cultural inmueble del centro histórico por cuenta de quienes de manera deliberada o no han efectuado intervenciones que van en contravía de su protección, demostrando que en los últimos años se ha consolidado como un actor de peso que no puede ser ignorado en la toma de decisiones de carácter local.

\section{El Plan Especial de Manejo y Protección [PEMP]}

En la actualidad, el centro histórico de Villa de Leyva cuenta con el Acuerdo Municipal 007 de 1996 (Concejo Municipal Villa de Leyva, 1996), formulada en su momento con el fin de proteger los valores históricos y estéticos de la población, que no obstante ya demuestra ser obsoleta ante las dinámicas que en las últimas décadas han puesto en riesgo su conservación.

Tal y como se mencionó anteriormente, a partir del desarrollo de la Ley General de Cultura (República de Colombia, 2008), la legislación colombiana contempla la existencia del Plan Especial de Manejo y Protección, un instrumento dirigido a la conservación de los valores patrimoniales de los centros históricos y su manejo, el cual tiene una jerarquía superior dentro del cuerpo normativo y al cual deben articularse los demás instrumentos de gestión del territorio. El espíritu de los PEMP se remonta al marco normativo español y es de obligatoria implementación, de acuerdo con lo establecido 
en el Decreto 1080 de 2015, "Por medio del cual se expide el Decreto Único Reglamentario del Sector Cultura” (República de Colombia, 2015). $\mathrm{Y}$ establece que en todos los inmuebles del grupo urbano que han sido declarados BIC de la nación, el PEMP deberá señalar el área afectada, la zona de influencia, el nivel permitido de intervención, las condiciones de manejo y el plan de divulgación que asegurará el respaldo comunitario a la conservación de estos bienes. A su vez, la norma permite que el Plan Especial de Manejo y Protección, sea renovado de manera periódica, en concordancia con las eventualmente cambiantes condiciones de los entornos patrimoniales.

Luego de haber transcurrido casi una década desde que comenzó a ser elaborado, culmina la elaboración del Plan, después de años de reclamos de parte de la comunidad por las demoras en su entrega al Ministerio de Cultura. La participación de diversos actores (administración local, candidatos a ocupar cargos en la administración pública, comunidad en general) en el proceso de la valoración, diagnóstico y formulación, ha hecho que hasta el último momento (2017) se hayan solicitado ajustes que, hasta donde la conservación de los valores patrimoniales del centro histórico lo permitió, fueron adoptados en el año 2019. Con su aprobación e implementación, se espera mitigar ciertas dinámicas que han venido causando deterioro en este escenario físico, aunque por más que haya sido aclarado, aún existen personas que creen que por sí mismo el PEMP va a solucionar los diversos problemas que por sus propias características posee este ámbito espacial y escapan de la injerencia del instrumento normativo.

Por su naturaleza, el PEMP es un instrumento que genera controversia entre algunos actores, principalmente entre quienes tienen intereses en el sector inmobiliario y comercial por cuanto delimita éstas actividades; como es apenas lógico, se comienzan a ver divisiones entre aquello habitantes que de manera justa demandan garantías para seguir ejerciendo las actividades de las cuales derivan su sustento diario, y quienes también de manera acertada reclaman la protección de este patrimonio cultural, en tanto se trata de un bien de naturaleza colectiva que debe ser preservado para las futuras generaciones y es motivo de orgullo y reconocimiento de los villaleyvanos, con cuyo deterioro pierden unos y otros.

\section{Los retos a futuro}

Lo que ocurra en el futuro inmediato con el centro histórico de Villa de Leyva depende del diálogo y de la concertación entre los diferentes actores que tienen intereses en este lugar. Más allá de lo que indique el PEMP, es necesaria la toma de conciencia de los habitantes acerca de la importancia de conservar los valores patrimoniales que hacen de este un escenario único y gracias a los cuales muchos han derivado su sustento, y la consideración que debería primar en esta reflexión es la de la primacía del interés general sobre el interés particular si es que se quiere dejar una herencia valiosa a las futuras generaciones.

Algunos sectores de la comunidad ven con optimismo la implementación del Plan Especial de Manejo y Protección pues lo consideran como la posibilidad de ponerle fin a los abusos que propios y extraños vienen cometiendo en contra del patrimonio cultural del centro histórico. Aunque en este sentido existen expectativas que ciertamente no se van a cumplir, por cuanto el PEMP se enfoca en aspectos muy específicos y por ende, no puede resolver todos los problemas que aquejan a la población. En este sentido, uno de los mayores retos se encuentra en el grado de articulación que se pueda lograr con otros instrumentos normativos del territorio, tales como el Plan Básico de Ordenamiento Territorial (Alcaldía Municipal de Villa de Leyva, 2004), vigente desde 2004 pero que se encuentra en mora de actualización y que puede brindar el marco para lograr un crecimiento del resto del casco urbano en armonía con el área declarada.

No se debe descartar el turismo como una opción válida para la economía de los habitantes locales y de la región, pero es necesario regularle y tener como prioridad el diseño de un Plan de Desarrollo Turístico que permita organizar esta actividad, vinculando y capacitando a los actuales operadores en el ejercicio responsable y en la transmisión de la importancia patrimonial del centro histórico a sus visitantes. Ello contribuiría a mitigar los efectos del deterioro que han dejado décadas de ejercicio sin control, cuyas huellas son visibles sobre la infraestructura de la zona declarada.

En el mediano y largo plazo, debería ser una consideración de primer orden facilitar las condiciones para permitir nuevamente el disfrute de los valores patrimoniales del centro histórico por parte de todos los habitantes del municipio de Villa de Leyva antes que, por parte de los turistas, brindando espacios para su conocimiento, reconocimiento y apropiación, en línea con el 
espíritu del PEMP. Ello implica, entre otras cosas, crear las facilidades para que la comunidad tenga la oportunidad de recrear sus prácticas en este escenario y para que sea tenida en cuenta como principal beneficiaria en los proyectos propuestos por la administración local.

Finalmente, también es necesario fortalecer las instituciones locales por medio de la capacitación de los funcionarios públicos y la aplicación rigurosa de sanciones para garantizar el cumplimiento de la normativa y evitar los abusos de quienes aprovechan la existencia de vacíos para desarrollar actividades que van en detrimento del centro histórico, ampliando además su capacidad operativa.

\section{Conclusiones}

A lo largo del documento se expuso la manera como las diversas dinámicas presentes actualmente en la zona de estudio (gentrificación, turistificación, desarrollo inmobiliario sin control) están amenazando la preservación de los valores patrimoniales que elevaron al centro histórico de Villa de Leyva a la máxima categoría de declaratoria del patrimonio cultural en Colombia, teniendo como base la conservación de la traza urbana y la existencia de una arquitectura propia del periodo colonial que era testimonio de la forma de ocupación del territorio propia de los españoles, y cómo se espera que la implementación del Plan Especial de Manejo y Protección ayude a mitigar los efectos del éxito que como nodo de actividades turísticas ha tenido la población. Este caso de estudio sirve como referente para otros tejidos urbanos con valor patrimonial que le apuestan a la promoción del turismo como fuente de ingresos económicos sin encontrarse suficientemente preparados para ello (infraestructura adecuada, capacitación a operadores, existencia de un Plan de Desarrollo Turístico).

La existencia de una comunidad conocedora de su patrimonio cultural, consciente de su singularidad y de la importancia de su preservación, ha resultado ser decisiva para evitar acciones que hubieran podido ocasionar mayores afectaciones sobre la conservación de los valores patrimoniales del centro histórico de Villa de Leyva. Sin embargo, ello no es suficiente. La limitada capacidad operativa de la administración local, que tiene como una de sus consecuencias la falta de control sobre todas las intervenciones físicas que allí se realizan, aunada a la escasa imposición de sanciones o multas, ha creado la noción entre la población de que no existe castigo para quienes con sus actuaciones afectan el bien común y que progresivamente han contribuido a desvirtuar aquellas cualidades que desde lo urbano arquitectónico fueron decisivas para otorgar a este lugar el reconocimiento como Bien de Interés Cultural del ámbito Nacional.

La progresiva vinculación de diferentes actores en los procesos de planificación y de toma de decisiones que tienen incidencia en el futuro del centro histórico y el territorio contribuirá a atenuar los efectos de la gentrificación y de la turistificación que ya son visibles, y al mismo tiempo garantizará que la esperada implementación del Plan Especial de Manejo y Protección, si bien no estará exenta de controversias por cuanto puede llegar a afectar diversos intereses, será acogida y respaldada por quienes allí residen.

En esta tarea el papel de la administración local como mediadora será fundamental, y reclama un mayor protagonismo y capacidad de maniobra en coordinación con las autoridades del orden nacional por parte de quienes la conforman, en concordancia con lineamientos internacionales como los establecidos en la Declaración de Amsterdam (Consejo de Europa, 1975), en la cual se valoran inicialmente las estructuras físicas que conforman los centros históricos pero al mismo tiempo se emite una voz de alerta frente al fenómeno de la gentrificación, o la Declaración de X'ian sobre la conservación del entorno de las estructuras, sitios y áreas patrimoniales (International Council on Monuments and Sites [ICOMOS], 2005) en la que se reconoce la importancia de involucrar a la población local en la gestión del patrimonio cultural y de capacitar a los encargados de su protección.

\section{Referencias bibliográficas}

Anderson, S. (1999). Memory without Monuments: Vernacular Architecture. Traditional Dwellings and Settlements Review, 11 (1), 1322. Recuperado el 23 de octubre de 2020, https://www.jstor.org/stable/41757728?s $\underline{\mathrm{eq}}=1$

Alcaldía municipal de Villa de Leyva (2004). Plan Básico de Ordenamiento Territorial.

Ancízar, M. (1956). Peregrinación de Alpha: Por las provincias del norte de la Nueva Granada, en 1850-51. Bogotá: Empresa Nacional de Publicaciones.

Ariza, A. (1972). El valle de Nuestra Señora de Leiva. Bogotá: Ed. Kelly. 
Bertoncello, R. (2006). Turismo, territorio y sociedad. El "mapa turístico de $\mathrm{La}$ Argentina”. En A. Geraiges de Lemos, M. Arroyo y M. Silveira (Ed.). América Latina: cidade, campo e turismo (pp. 317-335). San Pablo: Consejo Latinoamericano de Ciencias Sociales.

Concejo Municipal Villa de Leyva (1989). Acuerdo 004 de 1989.

Concejo Municipal Villa de Leyva (1996). Acuerdo 007 de 1996.

Consejo de Europa (1975). Declaración de Amsterdam.

Contraloría General de la República (1936). Geografía Económica de Colombia. Boyacá. Bogotá: Imprenta Nacional.

Costa, E. \& Alvarado-Sizzo, I. (2019). Heterotopía patrimonial: Concepto para estudios latinoamericanos. Scripta Nova. Revista Electrónica de Geografía y Ciencias Sociales, 23 (620), 1-31. Recuperado el 6 de febrero de 2020,

http://revistes.ub.edu/index.php/Scripta Nova/article/view/22329

Departamento Administrativo Nacional de Estadística [DANE] (2011). Estimaciones de población 1985-2005 y proyecciones de población 205-2020 total municipal por área. Recuperado el 22 de enero de 2014, https://www.dane.gov.co/index.php/esta disticas-por-tema/demografia-y-poblacion

Fals, O. (1973). El hombre y la tierra en Boyacá. Desarrollo histórico de una sociedad minifundista. Bogotá: Punta de Lanza.

Hiernaux, D. \& González, C. (2014). Turismo y gentrificación: Pistas teóricas sobre una articulación. Revista de Geografía Norte Grande, (58), 55-70. Recuperado el 6 de febrero de 2020 , https://dx.doi.org/10.4067/S071834022014000200004

International Council on Monuments and Sites, ICOMOS (2005). Declaración de X'ian sobre la conservación del entorno de las estructuras, sitios y áreas patrimoniales.

Langebaek, C. (2000). Arqueología regional en el Valle de Leiva: Proceso de ocupación humana en una región de los Andes orientales de Colombia. Bogotá: Instituto Colombiano de Antropología e Historia

Martín-Barbero, J. (2008). Comunicación y Culturas en América Latina. Barcelona: Anthropos Editorial.
Ministerio de Ambiente, Vivienda y Desarrollo Territorial (2010). Decreto 926 de 2010. Por el cual se establecen los requisitos de carácter técnico y científico para construcciones sismo resistentes NSR-10. 19 de marzo de 2010. D. O. 47.663.

Ministerio de Cultura (2015). Decreto 1080. Por medio del cual se expide el Decreto Reglamentario Único del Sector Cultura. 26 de mayo de 2015. D.O. 49.523.

Molano, J. (1990). Villa de Leiva: ensayo de interpretación social de una catástrofe ecológica. Bogotá: Fondo FEN.

Organización de las Naciones Unidas [ONU] (2015). Objetivos de desarrollo sostenible. Recuperado el 6 de febrero de 2020, https://www.un.org/sustainabledevelopm ent/es/objetivos-de-desarrollo-sostenible/

Pulgarín, Y. (2018). Memoria, espacialidad y culturas constructivas. La vivienda vernácula de la Subregión de Ricaurte Alto e Iguaque, departamento de Boyacá, Colombia (Tesis de doctorado en Arquitectura). Universidad Nacional Autónoma de México, Ciudad de México.

República de Colombia (1997). Ley 397 de 1997. Por la cual se desarrollan los articulos 70, 71 y 72 y demás articulos concordantes de la Constitución Politica y se dictan normas sobre patrimonio cultural, fomentos y estimulos a la cultura, se crea el Ministerio de Cultura y se trasladan algunas dependencias. 7 de agosto de 1997. D.O. No. 43.102.

República de Colombia (2008). Ley 1185 de 2008. Por la cual se modifica y adiciona la Ley 397 de 1997 -Ley General de Cultura-y se dictan otras disposiciones. 12 de marzo de 2008. D. O. 46.929.

Rodríguez, J., Cota, A., Salguero, O. \& GarcíaGarcía, E. (2018). Gentrificación y Turistificación en los Barrios, "Turismofobia" en la Tele y Hegemonía de la Marca Granada. Barcelona: Pollen Ediciones.

Smith, N. (1996). La nueva frontera urbana. Ciudad revanchista y gentrificación. Madrid: Traficantes de Sueños.

Vásquez, C. (1996). La Gentrificación. Un modelo de Segregación Socio Espacial en Ciudades Postindustriales. Madrid: Universidad Autónoma de Madrid. 